\title{
Normas de manejo y tratamiento de las Infecciones de Transmisión Sexual (ITS)*. Primera parte
}

\author{
Comité Normas Infecciones de Transmisión Sexual - Ministerio de Salud de Chile
}

Sexually Transmitted Infections: Guidelines for their diagnosis and treatment. First Part.

\author{
Autores: \\ Ester Santander C., Centro de ETS Hospital San José, Servicio de Salud \\ Metropolitano Norte. \\ Felix Fich Sch., Pontificia Universidad Católica de Chile. \\ Aurelio Salvo L., Centro de ETS Hospital Dr. Sótero del Río, Servicio de Salud Metro- \\ politano Sur Oriente. \\ Genoveva Pacheco L., Encargada Programa ITS y Programa de la Mujer, \\ Servicio de Salud Metropolitano Occidente. \\ M. Isabel Mendoza V., Encargada Programa ITS y VIH/SIDA, Servicio de Salud Bíobío. \\ Carmen Garcés I., Encargada Programas de VIH/SIDA y ETS, de la Mujer y \\ Salud Pueblos Indígenas. \\ Manuel Amigo M., Coordinador Consultorio Adosado Especialidades Hospital Re- \\ gional Talca. \\ Sara Villalobos M., Coordinadora Programas de VIH/SIDA y ETS Servicio de Salud \\ Osorno. \\ Maritza García O., Unidad de Vigilancia Epidemiológica, Departamento de \\ Epidemiología. Ministerio de Salud. \\ Aurora Maldonado B., Sección Bacteriología, Instituto de Salud Pública. \\ Pilar Planet Marín, Ministerio de Salud.
}
Coordinación: Carolina Peredo C., Encargada Proyecto ETS Fondo Global CONASIDA, Ministerio de Salud.

\section{Colaboradoras Sigrid Domke \\ primera redacción: Andrea Barrera}

Colaboradores Aníbal Hurtado P., Hospital del Salvador, Departamento de redacción final: $\quad$ Dermatología, Facultad de Medicina Universidad de Chile.

René Castro Santoro, Encargado de Programa Salud de la Mujer, Ministerio de Salud.

*Nota del editor: una versión completa de estas Normas puede ser consultada en http://www.minsal.cl/ici/guias_clinicas.html Los cambios a las normas fueron propuestos y validados en un taller el año 2004, con representantes de todos los Centros de ETS del país, revisadas y actualizadas por el Comité Técnico Asesor de las ITS del Ministerio de Salud durante el año 2007. 


\section{Índice}

\section{Primera parte}

Presentación

Introducción

Las infecciones de transmisión sexual

Epidemiología de las infecciones de transmisión sexual

Actividades de la Unidad de Atención y Control en Salud Sexual (UNACESS)

Consulta especializada de morbilidad en ITS

Control especializado de morbilidad en ITS

Consulta de salud sexual

Control de salud sexual

Atención a víctimas de violencia sexual 187

Educación personalizada 187

Consejería para la gestión de riesgo de ITS 188

Consejería pre y post prueba de ELISA para VIH 188

Manejo de la(s) pareja(s) / contacto(s) sexual(es) 188

\section{Presentación}

Las infecciones de transmisión sexual (ITS) constituyen una serie de infecciones y/o enfermedades transmisibles que se caracterizan porque su principal modalidad de transmisión es la vía sexual. El control de las ITS es fundamental para mejorar el nivel nacional de la salud sexual y reproductiva de la población de nuestro país.

Frente a esta necesidad y tomando en consideración la implementación de la Reforma de la Salud, la legalidad vigente y los avances tecnológicos se convocó a un equipo multidisciplinario, constituido por un grupo de expertos de vasta experiencia y manejo en el tema, para la elaboración de esta "Norma de Manejo y Tratamiento de las Infecciones de Transmisión Sexual”.

Este documento contempla en sus contenidos un modelo de atención que integra los aspectos biopsicosociales de las personas en cuanto al manejo clínico y a la consejería en estas infecciones excluyendo el VIH, que cuenta con normativa propia, y a las acciones relacionadas con la Educación en Salud Sexual.

En nombre del Gobierno, del Ministerio de Salud y de la Comisión Nacional del Sida, hacemos llegar nuestro reconocimiento a quienes colaboraron en la creación, reformulación de este documento, así como también nuestro estímulo a los equipos de gestión y tratantes, que permitirán su implementación y puesta en marcha en el ámbito de toda la Red Asistencial.

\footnotetext{
* En ejercicio del cargo al momento de promulgarse este documento.
} 


\section{Introducción}

La Reforma de Salud en Chile, centrada en la eficiencia de los Servicios de Salud y en los derechos exigibles por los ciudadanos, nos obliga, en el cumplimiento de esos derechos, a contar con un modelo integral de atención de salud, con enfoque de género, con normas y procedimientos actualizados y recursos humanos calificados.

Los establecimientos de la red asistencial, con roles definidos y complejidad diversa, deben realizar acciones de:

- Promoción.

- Prevención.

- Detección precoz y control de enfermedades.

- Tratamiento y recuperación.

- Rehabilitación y cuidados paliativos.

Dentro de los objetivos sanitarios la prevención y la atención de las ITS constituyen una condición prioritaria, por la magnitud del problema a nivel nacional, por su vinculación con el VIH/SIDA, y por los efectos que causa en la calidad de vida de las personas desde el punto de vista bio-psico-social.

Tabla 1. Síndromes de ITS comunes, sus patologías y sus agentes etiológicos

\begin{tabular}{|c|c|c|}
\hline Síndrome clínico & Patologías asociadas & Principal agente etiológico \\
\hline Descarga uretral & $\begin{array}{l}\text { Uretritis } \\
\text { Epididimitis }\end{array}$ & $\begin{array}{l}\text { - Neisseria gonorrhoeae. } \\
\text { - Chlamydophila trachomatis } \\
\text { - Mycoplasma genitalium } \\
\text { - Ureaplasma urealyticum } \\
\text { - Otros }\end{array}$ \\
\hline Descarga vaginal & $\begin{array}{l}\text { Cervicitis mucopurulenta } \\
\text { Vulvovaginitis } \\
\text { Vaginosis bacteriana (VB) }\end{array}$ & $\begin{array}{l}\text { - Neisseria gonorrhoeae } \\
\text { - Chlamydophila trachomatis } \\
\text { - Candida albicans } \\
\text { - Trichomonas vaginalis } \\
\text { - Bacterias asociadas a la VB } \\
\text { - Otros }\end{array}$ \\
\hline Dolor abdominal bajo & $\begin{array}{l}\text { Enfermedad pélvica } \\
\text { inflamatoria aguda }\end{array}$ & $\begin{array}{l}\text { - Neisseria gonorrhoeae } \\
\text { - Chlamydophila trachomatis } \\
\text { - Otros }\end{array}$ \\
\hline $\begin{array}{l}\text { Lesiones ulcerativas } \\
\text { genitales }\end{array}$ & $\begin{array}{l}\text { Herpes } \\
\text { Sífilis } \\
\text { Chancroide } \\
\text { Linfogranuloma venéreo }\end{array}$ & $\begin{array}{l}\text { - Virus herpes simplex tipo } 1 \text { y } 2 \\
\text { (VHS-1, VHS-2) } \\
\text { - Treponema pallidum. } \\
\text { - Haemophilus ducreyi } \\
\text { - Chlamydophila trachomatis } \\
\text { L1, L2 y L3 }\end{array}$ \\
\hline $\begin{array}{l}\text { Lesiones vegetantes } \\
\text { genitales }\end{array}$ & $\begin{array}{l}\text { Condiloma acuminado } \\
\text { Condiloma plano sifilítico } \\
\text { Molusco contagioso }\end{array}$ & $\begin{array}{l}\text { - Virus papiloma humano (VPH) } \\
\text { - Treponema pallidum } \\
\text { - Poxvirus }\end{array}$ \\
\hline
\end{tabular}

En este contexto, el Ministerio de Salud ha elaborado estas Normas que se sustentan en el Código Sanitario, DFL N 725 de 1967 y en el Reglamento, Decreto $\mathrm{N}^{\mathrm{o}} 206$ del 2005, ambos del Ministerio de Salud sobre Infecciones de Transmisión Sexual, que establece disposiciones generales acerca de las acciones de salud relacionadas y los lineamientos para la educación en salud sexual.

\section{Las infecciones de transmisión sexual}

Las infecciones de transmisión sexual constituyen un grupo heterogéneo de patologías transmisibles, cuyo único elemento en común es el compartir la vía sexual como mecanismo de transmisión.

El cambio de concepto, acuñado por la Organización Mundial de la Salud (OMS) en el año 1998, que sustituye la terminología de Enfermedades de Transmisión Sexual (ETS) por el de Infecciones de Transmisión Sexual (ITS) se sustenta, en que el término "Enfermedad", es inapropiado para designar a aquellas infecciones que son asintomáticas y que pasan desapercibidas para las personas con consecuencias, en ocasiones, irreversibles

Las manifestaciones clínicas comprometen, en la mayoría de los casos, el área genital y las mucosas, pero en otros tienen manifestaciones sistémicas. El impacto en salud pública está dado por las complicaciones y secuelas que pueden presentar, principalmente en mujeres y recién nacidos, y su relación con el aumento de la transmisibilidad del virus de la inmunodeficiencia humana (VIH), desde y hacia las personas infectadas con otra ITS.

Las ITS se pueden clasificar tomando en consideración diferentes aspectos como el agente causal, la patología que produce o los síntomas asociados, pudiendo agruparse varias patologías bajo un conjunto de síntomas.

Esta característica ha permitido el desarrollo de dos estrategias de abordaje diferente, el manejo etiológico y el manejo sindrómico. Esto con el propósito de favorecer el tratamiento oportuno de estas infecciones.

Se denomina manejo etiológico al tratamiento que se brinda cuando hay certeza absoluta del agente causal de la infección, y manejo sindrómico al tratamiento que se otorga basándose en la clasificación de las patologías en grupos sindrómicos de acuerdo a sus manifestaciones clínicas. Este manejo se recomienda cuando no existen posibilidades de llegar a un diagnóstico etiológico o si se tiene certeza de que la persona que consulta, no volverá a control (Tabla $1)$. 


\section{Epidemiología de las infecciones de} transmisión sexual

\section{Antecedentes}

Las enfermedades de transmisión sexual $\left(\right.$ ETS $\left.^{1}\right)$, son afecciones frecuentes que pueden tener consecuencias serias para la salud de la población y configuran un problema de salud pública dada su amplia distribución. Son prevenibles, diagnosticables y tratables ${ }^{2}$.

La OMS estimó la ocurrencia de 333 millones de ETS en el año 1998 para todo el planeta, de ellas 36 millones en América Latina y el Caribe ${ }^{3}$. Las más frecuentes en la actualidad son: vaginosis bacteriana, herpes genital, clamidiasis, blenorragia (gonorrea), tricomoniasis, candidiasis, infecciones por virus papiloma humano, hepatitis B, sífilis y la infección por VIH/ SIDA.

El control de estas infecciones en el concierto mundial es fundamental para mejorar la salud reproductiva de toda población. El impacto que tienen las ITS en las mujeres y los niños, sumado a la vinculación que existe entre ellas y la prevención de la infección por VIH, representan para los profesionales de la salud una preocupación permanente debido a que pueden incrementar la probabilidad de adquirir y transmitir el VIH, constituyéndose en un factor de riesgo. Se estima que una enfermedad de transmisión sexual aumenta hasta cinco veces el riesgo de infectarse con el VIH.

La OMS y el Programa Conjunto de las Naciones Unidas dedicado al VIH/SIDA. (ONUSIDA) consideran que la vigilancia de las ETS es un componente clave de los sistemas de vigilancia del VIH y SIDA de segunda generación ${ }^{4}$; el Ministerio de Salud, a través del Departamento de Epidemiología de la División de Planificación Sanitaria, dependiente de la Subsecretaría de Salud Pública, ha considerado necesario reforzar esta vigilancia, considerando la contribución potencial de estas enfermedades a la transmisión de la infección por VIH.

En el año 1999, la CONASIDA, del Ministerio de Salud, implementó el Sistema de Vigilancia Centinela de ETS en seis centros de atención distribuidos a lo largo del país, incorporando el año 2003 un séptimo centro centinela. Todos estos centros disponen de técnicas de laboratorio para la confirmación etiológica de las patologías que se notifican, con excepción de infección por virus papiloma y herpes genital que son diagnósticos generalmente, clínicos.

Si bien estos centros no son representativos de la población general, ya que corresponden a centros de atención exclusiva de ETS, la información que recogen a través de la ficha de "Notificación de casos de ETS", es de interés para el Programa.

\section{Sistema de vigilancia}

En Chile, el Decreto Supremo $158^{5}$, establece que las ETS, son enfermedades de declaración obligatoria, que deben ser notificadas a la Autoridad Sanitaria por el establecimiento asistencial, tanto público como privado. Establece que la gonorrea, sífilis e infección por VIH/SIDA, son de notificación universal (todos los casos) y que otras ETS, con excepción de las mencionadas, serán de vigilancia exclusiva a través de establecimientos centinelas. Además, se consideran como agente sujeto a vigilancia de laboratorio el Treponema pallidum, y el VIH (Art. 9, DS.158).

En abril de 2005, el Departamento de Epidemiología se hace cargo de la vigilancia de la infección por VIH/ SIDA y ETS, comenzando por modificar el sistema de notificación de sífilis en la mujer embarazada, sífilis congénita e infección por VIH/SIDA. Durante el año 2007 se inició la revisión de la vigilancia centinela en dos enfermedades: infección por clamidias e infección por virus papiloma.

Las razones para priorizar la vigilancia en estas dos patologías se debe principalmente a que:

- Chlamydophila trachomatis es una de las bacterias de transmisión sexual más frecuentes en el mundo. La OMS estima que 92 millones de nuevos casos ocurren cada año. Se ha demostrado que 70 a $90 \%$ de las infecciones por C. trachomatis en la mujer son asintomáticas, pudiendo persistir por meses o años. Su mayor incidencia se presenta en la adolescencia y en mujeres bajo 25 años de edad. En el hombre, la infección suele ser asintomática (en 6 a $11 \%$ de los casos), especialmente en los adolescentes ${ }^{6}$.

\footnotetext{
${ }^{1}$ Dixan MR, Wasserheit J. La cultura del silencio. Infecciones del tracto reproductivo entre las mujeres del tercer mundo. Nueva York: International Women's Health Coalition, 1991: 131-3.

2 Salud sexual y reproductiva. Washington, DC: OPS, OMS, 1995. Comunicación para la salud (8): 17-8.

${ }^{3}$ Dallabeta MD, Gina A. El control de las enfermedades de transmisión sexual: un manual para el diseño y la administración de programas. Washington, DC: OPS, 1997: 3-24, 174-81.

${ }^{4}$ Vigilancia del VIH de segunda generación. El próximo decenio, OMS/ONUSIDA, 2000. Organización Mundial de la Salud y Programa Conjunto de las Naciones Unidas sobre el VIH/SIDA.

${ }^{5}$ Ministerio de Salud, 2004 Decreto supremo 158.

${ }^{6}$ Martínez T., M. Angélica. Diagnóstico microbiológico de Chlamydia trachomatis: Estado actual de un problema. Rev Chil Infectol [online]. 2001, vol. 18, no.4 [citado 08 Agosto 2007], p. 275-284. Disponible en la World Wide Web: <http://www.scielo.cl/scielo.php?script=sci_arttext\&pid=S0716$10182001000400006 \& \operatorname{lng}=$ es\&nrm=iso>. ISSN 0716-1018.
} 
Los costos atribuidos al tratamiento de las secuelas de la infección en la mujer, a menudo irreversibles, como son la enfermedad inflamatoria pelviana (EIP), embarazos ectópicos e infertilidad, la convierten en la infección de transmisión sexual (ITS) más cara después de la infección por VIH.

El estudio de carga de enfermedad realizado en Chile en 1996, muestra que los AVISA (carga de enfermedad) por C. trachomatis para el total de la población, corresponden a 2.652 años.

- La infección por el virus papiloma humano (VPH) es la enfermedad de transmisión sexual más frecuente, con mas de 630 millones de infectados en el mundo y de éstos 190 millones con infección clínica. En E.U.A. se espera que al menos $50 \%$ de las mujeres y hombres sexualmente activos contraerán la infección genital por VPH en algún momento de sus vidas y que al menos $80 \%$ de mujeres habrá contraído una infección genital por VPH al llegar a los 50 años de edad ${ }^{7}$.

Este virus afecta principalmente la piel y las mucosas genitales, es causante de lesiones benignas, como verrugas o condilomas y lesiones pre-cancerosas y cánceres, siendo el cáncer cérvico-uterino el más frecuente. Además, se conoce que puede jugar un rol importante en otros cánceres de ano, vulva, vagina, pene y oro-faríngeo.

Existen más de 100 tipos o cepas diferentes de este virus y aproximadamente 30 de ellos son transmitidos sexualmente. Estos últimos se dividen en virus de "alto riesgo", a los cuales se les relaciona con el desarrollo de lesiones intra-epiteliales escamosas de bajo y alto grado y cáncer invasor (p. ej.: c16, 18, 31,33 , etc) y de "bajo riesgo", que se asocian a la producción de verrugas genitales, lesiones intraepiteliales escamosas de bajo grado y papilomatosis respiratoria.

La mayoría de las personas infectadas por VPH no presentan síntomas y en $90 \%$ la infección desaparece a los dos años. Sin embargo, una pequeña proporción de mujeres presenta una infección persistente por VPH y si ésta es producida por un virus de "alto riesgo" se incrementa la probabilidad de presentar un cáncer cérvico-uterino.

En la Encuesta Nacional de Salud de Chile, (MINSAL, 2003) se estudió la infección por VPH en población de mujeres mayores de 17 años que habían iniciado relaciones sexuales. Los resultados muestran una prevalencia de 16 por 100 mujeres, cifra menor a lo estimado por la OMS, entre 18 y $25 \%$ de mujeres sexualmente activas, pero superior a lo detectado en España 3 a 6\%, la más baja de Europa. $\mathrm{Al}$ igual que en otros países, las más afectadas son las mujeres bajo 25 años de edad, situación esperada, dado que en este grupo se presentan los factores de riesgo más relevantes para adquirir este tipo de infección, como son; vida sexual activa y parejas múltiples. Cabe destacar que estas cifras van disminuyendo en edades mayores, siendo la prevalencia menor luego de los 50 años; sin embargo, estas son edades donde el riesgo de cáncer cérvico-uterino es mayor.

\section{Situación epidemiológica en Chile}

Sifilis: Definiciones y estadísticas

Sifilis primaria

Caso sospechoso: Caso clínico.

Caso confirmado: Caso clínico con confirmación de laboratorio y/o antecedentes de contacto con un caso confirmado.

Sifilis secundaria

Caso sospechoso: Caso clínico.

Caso confirmado: Caso clínico más confirmación de laboratorio con VDRL cuantitativo y prueba treponémica reactiva a títulos mayores de 1:4 diluciones.

Sifilis latente precoz

Caso sospechoso: Caso clínico.

Caso confirmado: Caso clínico más confirmación de laboratorio. Se recomienda confirmar con examen de LCR para descartar neurosífilis en personas con infección por VIH.

\section{Sifilis latente tardia}

Caso sospechoso: Caso clínico.

Caso confirmado: Caso clínico más confirmación de laboratorio.

\section{Neurosifilis}

Caso sospechoso: Caso clínico.

Caso confirmado: Caso clínico más confirmación de laboratorio.

Durante el período analizado de 44 años, el número de notificaciones de sífilis en todas sus formas ha experimentado una serie de variaciones, las que probablemente se deban a modificaciones en el sistema de registro y de notificación de casos, entre otras causas (Tabla 1). La Figura 1 muestra que desde 1992 comienza una disminución sostenida (de 38,3 por 100.000 hab

\footnotetext{
${ }^{7}$ Report To Congress Prevention Of Genital Human Papillomavirus Infection Centers For Disease Control And Prevention Department Of Health And Human Services Julie Louise Gerberding, M.D., M.P.H.Director Centers For Disease Control And Prevention, January 2004.
} 
a 17,9 por 100.000 hab el año 2007). Ello representa una disminución de 43,3\%.

En el año 2006 se registraron en el país 2.993 casos de sífilis en todas sus formas, alcanzando una tasa de 18,2 por 100.000 hab, mientras que en el año 2007 se registraron 2.968 casos de sífilis en todas sus formas, con una tasa de 17,9 por 100.000 hab. En ambos períodos la notificación se incrementó rápidamente a partir de los 15 años, aunque el pico se produjo en el quinquenio inmediatamente superior.

La curva se mantiene estacionaria hasta el rango entre 30 y 34 años, para luego descender paulatinamente (Figura 2).

Al analizar los casos por sexo, la concentración es levemente superior en las mujeres (56\% en el 2007). Esto se puede explicar por el alto tamizaje a las que son sometidas las mujeres, tanto en el control de embarazo, control ginecológico, entre otros programas, donde por norma se establece la solicitud del examen serológico (Figura 3).

\section{Sifilis congénita}

Caso sospechoso: Recién nacido $(\mathrm{RN})$ o mortinato de madre con sífilis no tratada o inadecuadamente tratada.

Caso confirmado: Caso sospechoso (RN o mortinato) más confirmación de laboratorio.

Entre el año 2001 y el 2007 el número de sífilis en mujeres embarazadas ha aumentado en $420 \%$, mientras que la sífilis congénita en igual período se ha incrementado en $132 \%$ (Tabla 3 ).

En Chile, a pesar de los altos indicadores de control de embarazo y atención profesional del parto, aún nacen niños con sífilis. Del total de casos de sífilis alrededor de $0,2 \%$ corresponden a casos de sífilis congénita. Según información del sistema de Enfermedades de Notificación Obligatoria (ENO), la tasa de notificación de sífilis congénita se ha mantenido estable durante los años 1999 al 2006, con una incidencia de 0,22 por 1.000 nacidos vivos y un leve aumento en relación al $2005(0,22$ y 0,18 por cada 1.000 nacidos vivos corregidos (NVC), respectivamente) (Figura 4).

Las regiones que presentan las mayores tasas acumuladas de sífilis congénita son: la II (Antofagasta), I (Tarapacá) y V (Valparaíso) (Figura 5).

Durante el 2007 hubo un incremento del 4,3\% de casos notificados de sífilis en mujeres embarazadas. En el mismo, 49 casos de sífilis congénita (Figura 6).

Gonorrea: Definiciones y estadisticas

Caso sospechoso: Caso compatible con la descripción clínica. Antecedentes de contacto con caso sospechoso.
Tabla 2. Casos y tasas de sífilis. Chile 1963- 2007

\begin{tabular}{|c|c|c|c|}
\hline Año & Población & n de casos & Tasa* \\
\hline 1963 & 8.183 .524 & 3.046 & 37,2 \\
\hline 64 & 8.379 .998 & 3.502 & 41,8 \\
\hline 65 & 8.572247 & 4.479 & 52,3 \\
\hline 66 & 8.760 .948 & 3.603 & 41,1 \\
\hline 67 & 8.948 .692 & 3.990 & 44,6 \\
\hline 68 & 9.134 .462 & 4.300 & 47,1 \\
\hline 69 & 9.317 .241 & 3.279 & 35,2 \\
\hline 1970 & 9.496 .014 & 1.464 & 15,4 \\
\hline 71 & 9.669 .935 & 3.217 & 33,3 \\
\hline 72 & 9.839 .683 & 2.992 & 30,3 \\
\hline 73 & 10.006 .524 & 2.681 & 26,9 \\
\hline 74 & 10.171 .727 & 3.922 & 38,6 \\
\hline 75 & 10.336 .560 & 5.252 & 50,8 \\
\hline 76 & 10.499 .098 & 5.722 & 54,5 \\
\hline 77 & 10.658 .494 & 6.858 & 64,3 \\
\hline 78 & 10.817 .638 & 10.248 & 94,7 \\
\hline 79 & 10.979 .419 & 83.93 & 76,4 \\
\hline 1980 & 11.146 .726 & 81.99 & 73,6 \\
\hline 81 & 11.318 .558 & 10.039 & 88,7 \\
\hline 82 & 11.492 .991 & 8.328 & 72,5 \\
\hline 83 & 11.671 .524 & 7.352 & 63,0 \\
\hline 84 & 11.855 .655 & 5.125 & 43,2 \\
\hline 85 & 12.046 .884 & 3.958 & 32,9 \\
\hline 86 & 12.246 .720 & 3.354 & 27,4 \\
\hline 87 & 12.454 .160 & 3.466 & 27,8 \\
\hline 88 & 12.666 .945 & 3.710 & 29,3 \\
\hline 89 & 12.882 .818 & 4.193 & 32,5 \\
\hline 1990 & 13.178 .782 & 4.282 & 32,5 \\
\hline 91 & 13.422 .010 & 5.017 & 37,4 \\
\hline 92 & 13.665 .241 & 5.238 & 38,3 \\
\hline 93 & 13.908 .473 & 4.958 & 35,6 \\
\hline 94 & 14.151 .708 & 4.705 & 33,2 \\
\hline 95 & 14.394 .940 & 4.128 & 28,7 \\
\hline 96 & 14.595 .504 & 3.574 & 24,5 \\
\hline 97 & 14.796 .076 & 3.633 & 24,5 \\
\hline 98 & 14.996 .647 & 3.507 & 23,4 \\
\hline 99 & 15.197 .213 & 3.797 & 25,0 \\
\hline 2000 & 15.397 .784 & 3.680 & 23,9 \\
\hline 01 & 15.571 .879 & 3.214 & 20,6 \\
\hline 02 & 15.745 .583 & 3.501 & 22,2 \\
\hline 03 & 15.919 .479 & 3.574 & 22,5 \\
\hline 04 & 16.093 .378 & 3.155 & 19,7 \\
\hline 05 & 16.267 .278 & 2.838 & 17,4 \\
\hline 06 & 16.432 .674 & 2.993 & 18,2 \\
\hline 07 & 16.598 .074 & 2.968 & 17,9 \\
\hline
\end{tabular}




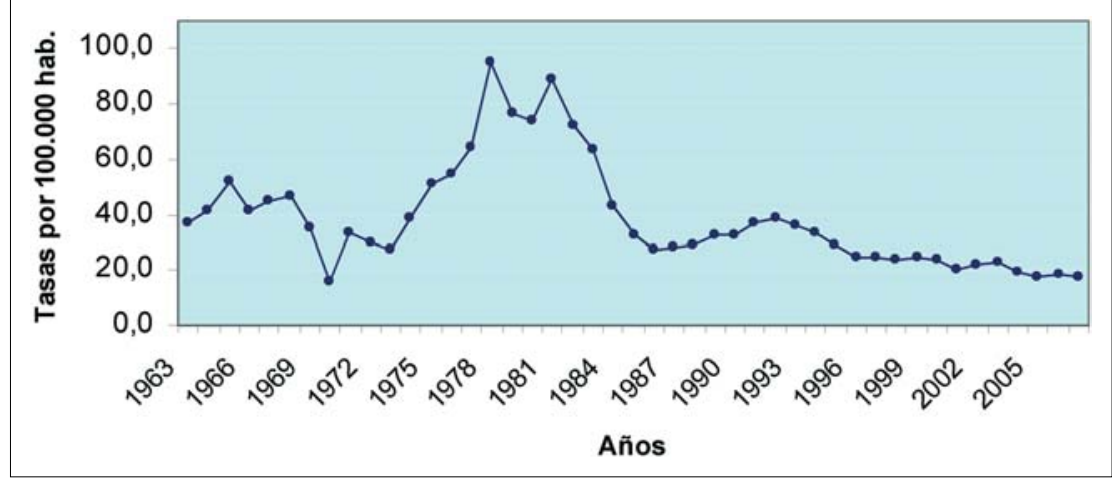

Figura 1. Tasas de incidencia de sífilis. Chile 1963-2007.
Caso confirmado: Caso clínicamente compatible que es confirmado en laboratorio (Tabla 4).

En las Figuras siguientes ( 7 y 8), se observa que la tasa de incidencia en Chile en el año 2002 fue de 12,8 por 100.000 hab, disminuyendo el año 2007 a 7,6 por 100.000 hab. Ello representa una disminución de 37,5\%; sin embargo, dada la sub-notificación de casos, hay que ser cuidadoso en la interpretación de las cifras.

Distribución por sexo. El 81\% de los casos notificados el 2007, correspondió a hombres, lo que se acerca a las estadísticas mundiales.

Figura 2. Tasas de sífilis/ $10^{5}$ hbtes. por grupos de edad. Chile 2006-2007.

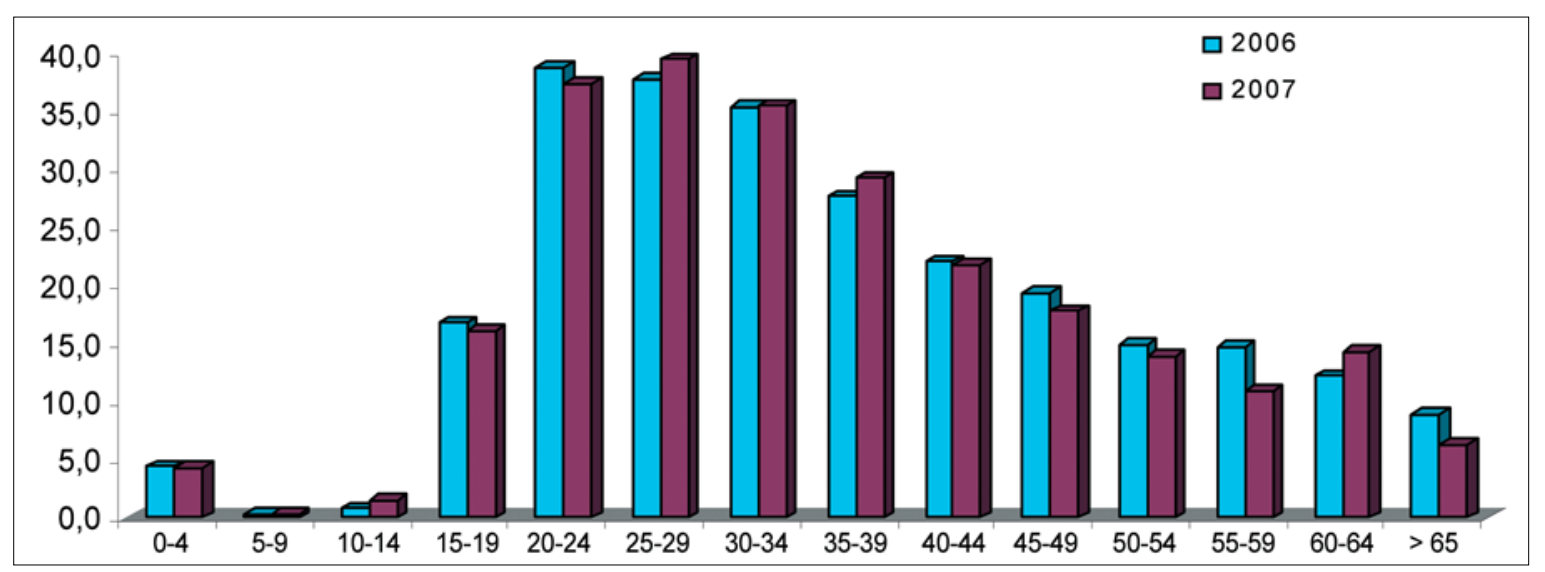

Figura 3. Tasas de sífilis por

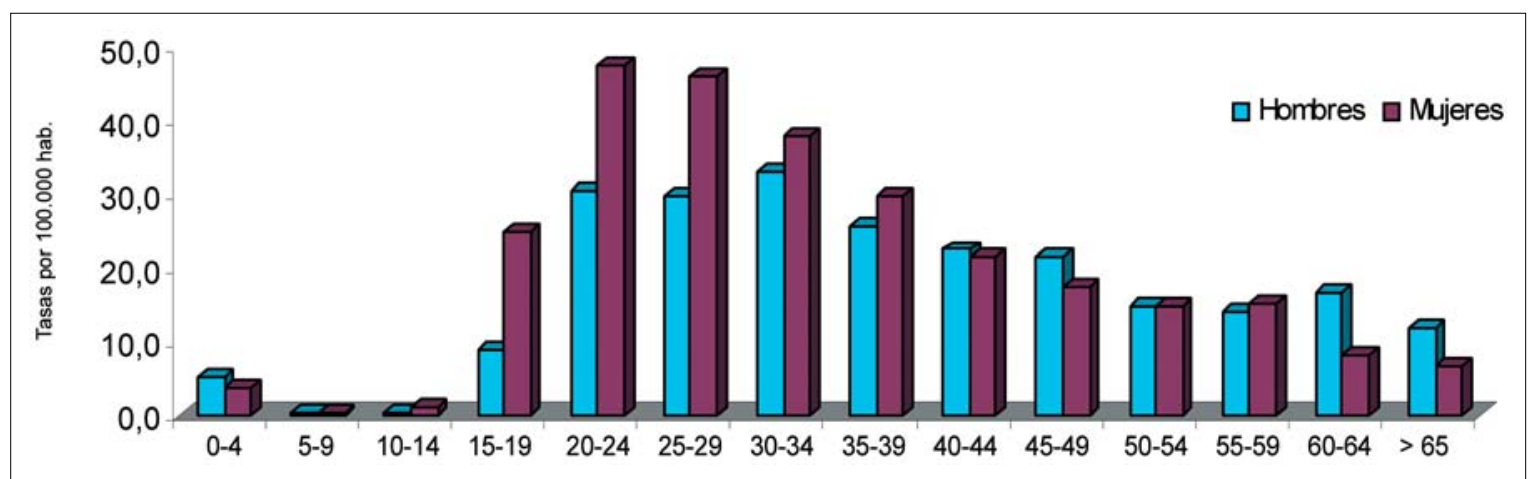

Tabla 3. Evolución total de partos, casos notificados de sífilis en embarazadas y sífilis congénita. Chile 2001-2007*

\begin{tabular}{|c|c|c|c|c|}
\hline Año & Total de partos & Sífilis en mujeres embarazadas (n) & Sífilis congénita (n) & Tasas por 1.000 NVC \\
\hline 2001 & 190.737 & 86 & 37 & 0,14 \\
\hline 02 & 184.290 & 240 & 65 & 0,26 \\
\hline 03 & 116.817 & 261 & 57 & 0,23 \\
\hline 04 & 109.212 & 299 & 61 & 0,25 \\
\hline 05 & 165.564 & 278 & 44 & 0,18 \\
\hline 06 & 162.717 & 346 & 53 & 0,22 \\
\hline $2007^{*}$ & 164.892 & 361 & 49 & 0,20 \\
\hline
\end{tabular}




\begin{tabular}{|c|c|c|c|}
\hline Año & Población & n de casos & Tasa* \\
\hline 1981 & 11.318 .558 & 12.836 & 113,4 \\
\hline 82 & 11.492 .991 & 11.413 & 99,3 \\
\hline 83 & 11.671 .524 & 12.289 & 105,3 \\
\hline 84 & 11.855 .655 & 12.758 & 107,6 \\
\hline 85 & 12.046 .884 & 12.400 & 102,9 \\
\hline 86 & 12.246 .720 & 13.525 & 110,4 \\
\hline 87 & 12.454 .160 & 13.066 & 104,9 \\
\hline 88 & 12.666 .946 & 10.809 & 85,3 \\
\hline 89 & 12.882 .818 & 8.411 & 65,3 \\
\hline 1990 & 13.178 .782 & 7.277 & 55,2 \\
\hline 91 & 13.422 .010 & 7.176 & 53,5 \\
\hline 92 & 13.665 .241 & 5.554 & 40,6 \\
\hline 93 & 13.908 .473 & 4.205 & 30,2 \\
\hline 94 & 14.151 .708 & 3.664 & 25,9 \\
\hline 95 & 14.394 .940 & 2.836 & 19,7 \\
\hline 96 & 14.595 .504 & 2.688 & 18,4 \\
\hline 97 & 14.796 .076 & 2.318 & 15,7 \\
\hline 98 & 14.996 .647 & 2.264 & 15,1 \\
\hline 99 & 15.197 .213 & 2.390 & 15,7 \\
\hline 2000 & 15.397 .784 & 2.485 & 16,1 \\
\hline 01 & 15.571 .879 & 2.155 & 13,8 \\
\hline 02 & 15.745 .583 & 2.014 & 12,8 \\
\hline 03 & 15.919 .479 & 1.901 & 11,9 \\
\hline 04 & 16.093 .378 & 1.718 & 10,7 \\
\hline 05 & 16.267 .278 & 1.601 & 9,8 \\
\hline 06 & 16.432 .674 & 1.313 & 8,0 \\
\hline $07 * *$ & 16.598 .074 & 1.258 & 7,6 \\
\hline \multicolumn{4}{|c|}{$\begin{array}{l}\text { *Tasas por } 100.000 \text { hab. Fuente: Boletín ENO } \\
\text { **Informe preliminar. }\end{array}$} \\
\hline
\end{tabular}

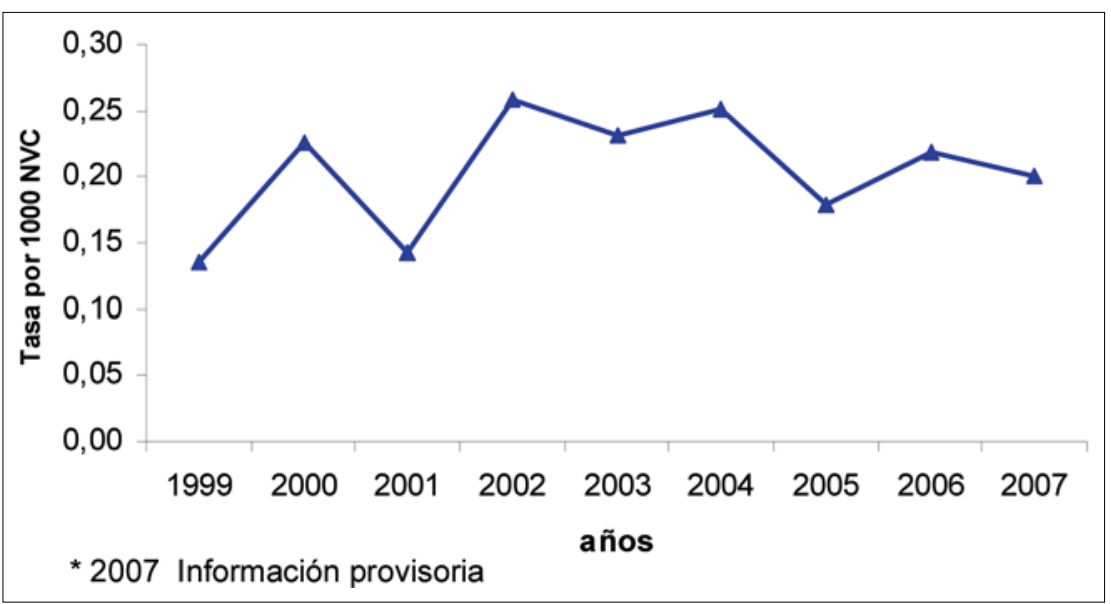

Figura 4. Tasa de notificación de casos de sífilis congénita. Chile, 1999-2007*. NVC: nacidos vivos conocidos

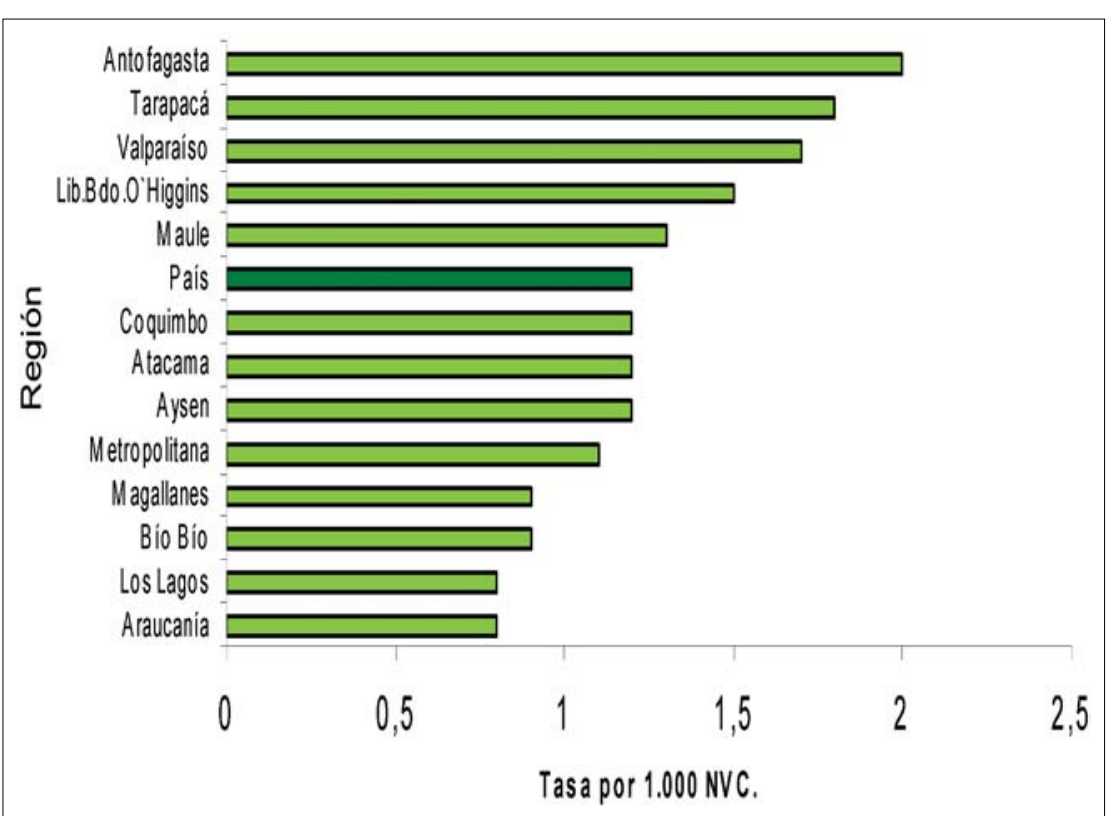

Figura 5. Tasa acumulada de sífilis congénita, por región de residencia. Chile, 1999-2006. NVC: nacidos vivos conocidos.

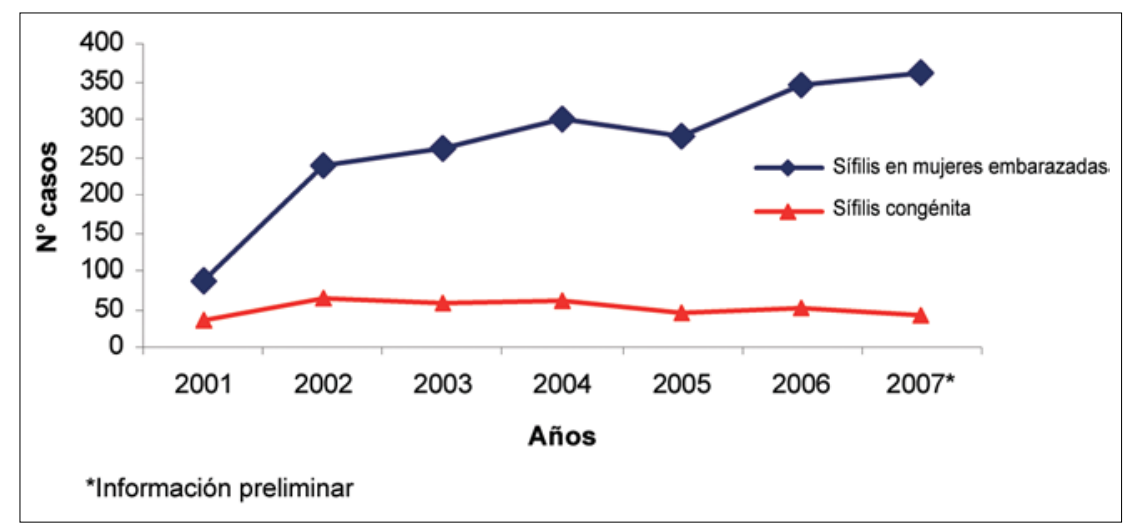

Figura 6. Casos de sífilis en mujeres embarazadas y sífilis congénita. Chile, 2001-2007* 


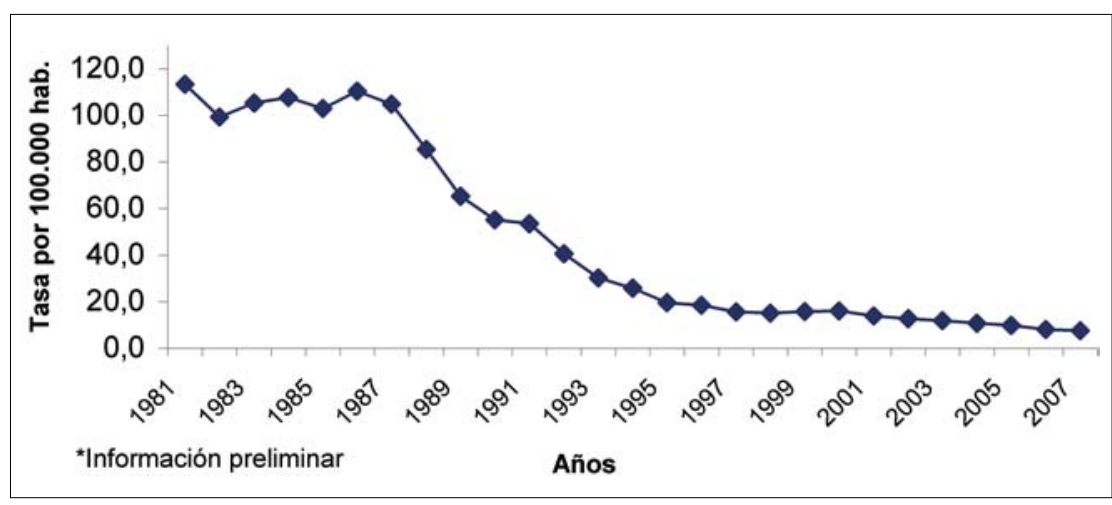

Figura 7. Tasa de incidencia de gonorrea. Chile, 1981-2007*.

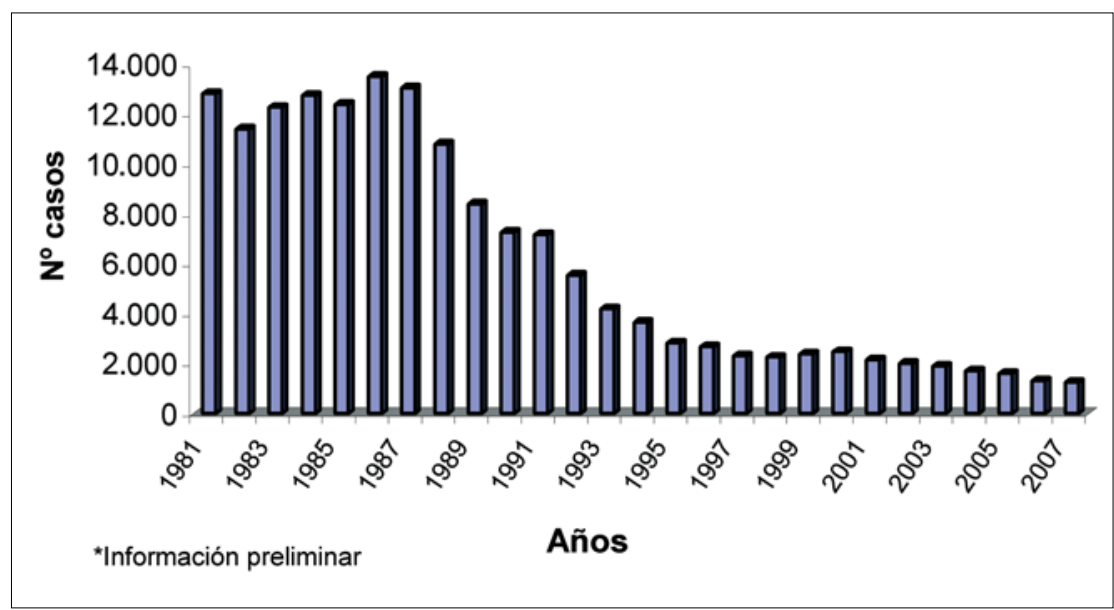

Figura 8. Número de casos de gonorrea. Chile, 1981-2007*.

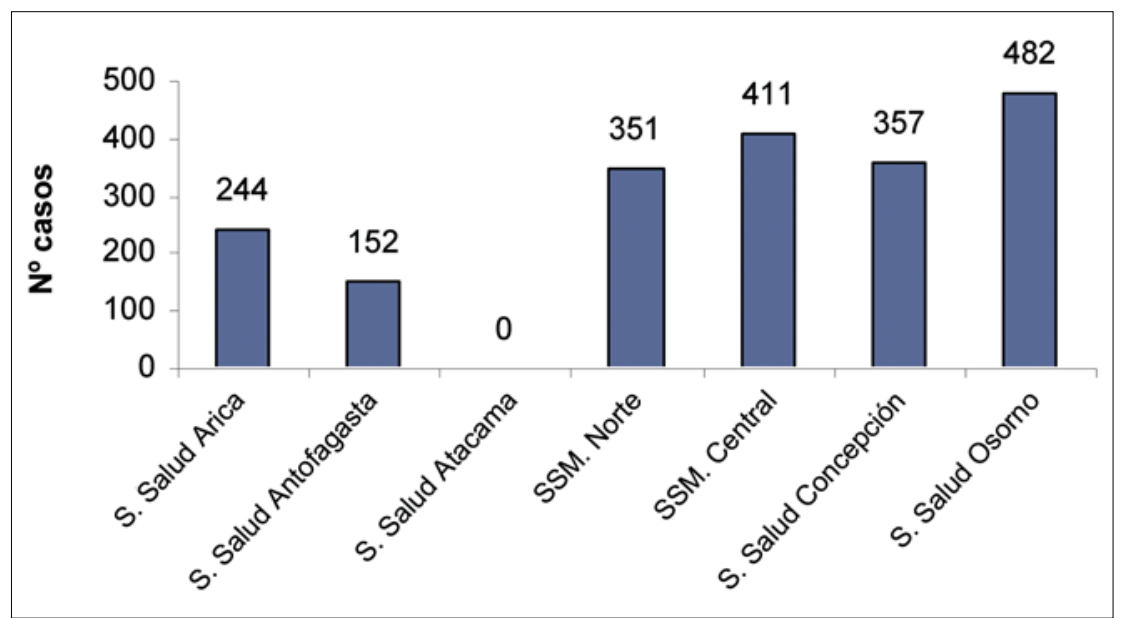

Figura 9. Total casos notificados según CETS. Chile, 2006.

\section{Vigilancia centinela de enfermedades de} transmisión sexual, Chile 2006

Durante el año 2006 se notificaron 1.997 casos de ITS en los centros centinela. Los centros que más casos notificaron fueron el Servicio de Salud Osorno y el Servicio de Salud Metropolitano Central con 24,1 y $20,6 \%$ respectivamente. El Servicio de Salud Atacama no registra casos notificados en el período analizado ${ }^{8}$. (Tabla 5, Figura 9).

En el total de casos notificados el condiloma acuminado y la sífilis, en todas sus formas, son los diagnósticos más frecuentes, concentrando $58,8 \%$ de los casos.

Al analizar la información por sexo, se aprecia que las mujeres concentran $57,3 \%$ de las notificaciones. El diagnóstico más frecuente en ambos sexos fue el condiloma acuminado/plano con $43,1 \%$ mientras que la sífilis, en todas sus presentaciones, concentró $15,7 \%$ del total de casos notificados (Tabla 6, Figura 10 y 11).

$\mathrm{Al}$ analizar la información por grupos de edad, se aprecia que en todos los rangos las mujeres son más afectadas. El mayor número de casos se concentra entre los 20 y 44 años (Tabla 7, Figura 12).

Respecto a la vía de exposición declarada por los pacientes atendidos en los CETS, $87,6 \%$ de ellos es por relaciones heterosexuales (Tabla 8).

En cuanto al número de parejas declaradas por los pacientes notificados, $52,2 \%$ declara tener 1 sola pareja sexual, mientras que $30 \%$ dice tener entre 2 y 4 parejas sexuales (Tabla 9).

Al analizar la información por profesión u oficio declarados las dueñas de casa y estudiantes concentran $38,1 \%$ de los casos (Tabla 10, Figura 13).

${ }^{8}$ Actualmente se está evaluando la continuidad de este centro como centro centinela.

\begin{tabular}{|lcr|}
\hline \multicolumn{3}{|c|}{$\begin{array}{c}\text { Tabla 5. Casos de ITS identificados en } \mathbf{7} \text { centros } \\
\text { centinelas. Chile } \mathbf{2 0 0 6}\end{array}$} \\
\hline Servicio de Salud & n de casos & $\%$ \\
\hline S.S. Arica & 244 & 12,2 \\
S.S. Antofagasta & 152 & 7,6 \\
\hline S.S. Atacama & 0 & 0,0 \\
S.S. Metropolitano Norte & 351 & 17,6 \\
\hline S.S. Metropolitano Central & 411 & 20,6 \\
S.S. Concepción & 357 & 17,9 \\
\hline S.S. Osorno & 482 & 24,1 \\
\hline Total & 1.997 & 100 \\
\hline Fuente: DEIS & & \\
\hline
\end{tabular}




\begin{tabular}{|lrrrr|}
\hline \multicolumn{5}{|c}{ Tabla 6. ITS observados en $\mathbf{7}$ centros centinelas. Chile 2006} \\
\hline Diagnóstico final & Hombres & \multicolumn{1}{c}{$\%$} & Mujeres & \multicolumn{1}{c|}{$\%$} \\
\hline Sifilis primaria & 35 & 1,8 & 10 & 0,5 \\
\hline Sífilis secundaria & 41 & 2,1 & 27 & 1,4 \\
\hline Sífilis latente precoz & 76 & 3,8 & 58 & 2,9 \\
\hline Sífilis latente tardía & 28 & 1,4 & 36 & 1,8 \\
\hline Gonorrea & 122 & 6,2 & 10 & 0,5 \\
\hline Clamidiasis & 1 & 0,1 & 5 & 0,3 \\
\hline Candidiasis & 14 & 0,7 & 120 & 6,1 \\
\hline Tricomoniasis & 1 & 0,1 & 36 & 1,8 \\
\hline UNG sin etiología definida & 99 & 5,0 & 96 & 4,8 \\
\hline Herpes simplex & 33 & 1,7 & 44 & 2,2 \\
\hline Condiloma acuminado/plano & 319 & 16,1 & 536 & 27,0 \\
\hline Vaginosis bacteriana & 0 & 0,0 & 158 & 8,0 \\
\hline Otro & 18 & 0,9 & 56 & 2,8 \\
\hline Total & 787 & 39,7 & 1.192 & 57,3 \\
\hline Nota: 18 casos sin información del diagnóstico final. Fuente: DEIS & \\
\hline
\end{tabular}

Tabla 7. Edad de los consultantes por ITS. CETS. Chile 2006

\begin{tabular}{|lrrrr} 
Grupos de edad & \multicolumn{2}{c}{ Hombres } & \multicolumn{2}{c}{ Mujeres } \\
(años) & n & $\%$ & n & \% \\
\hline$<1$ & 6 & 0,3 & 3 & 0,2 \\
1 a 4 & 1 & 0,1 & 2 & 0,1 \\
\hline 5 a 9 & 0 & 0,0 & 2 & 0,1 \\
\hline 10 a 14 & 2 & 0,1 & 19 & 1,0 \\
\hline 15 a 19 & 90 & 4,5 & 177 & 8,9 \\
\hline 20 a 24 & 167 & 8,4 & 295 & 14,8 \\
\hline 25 a 34 & 260 & 13,0 & 326 & 16,3 \\
\hline 35 a 44 & 156 & 7,8 & 221 & 11,1 \\
\hline 45 a 54 & 64 & 3,2 & 98 & 4,9 \\
\hline 55 a 64 & 38 & 1,9 & 32 & 1,6 \\
\hline 65 y más & 14 & 0,7 & 14 & 0,7 \\
\hline Sin información & 3 & 0,2 & 7 & 0,4 \\
\hline Total & 801 & 40 & 1196 & 60 \\
\hline
\end{tabular}

Fuente: DEIS
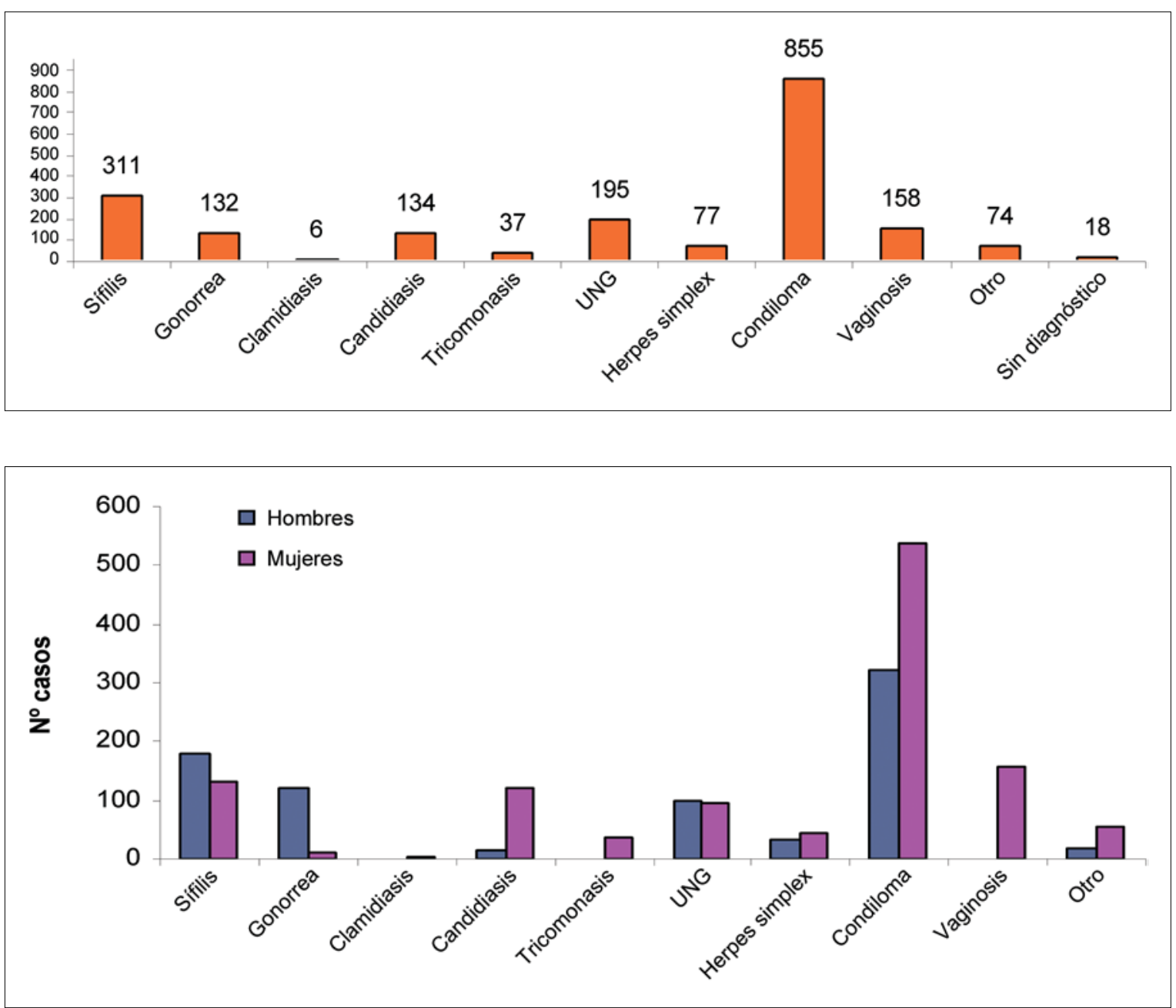

Figura 10. Total casos notificados según diagnóstico CETS. Chile, 2006.
Figura 11. Total casos notificados según diagnóstico y sexo, CETS. Chile, 2006. 
Figura 12. Total casos notificados en CETS según grupos de edad y sexo. Chile, 2006.

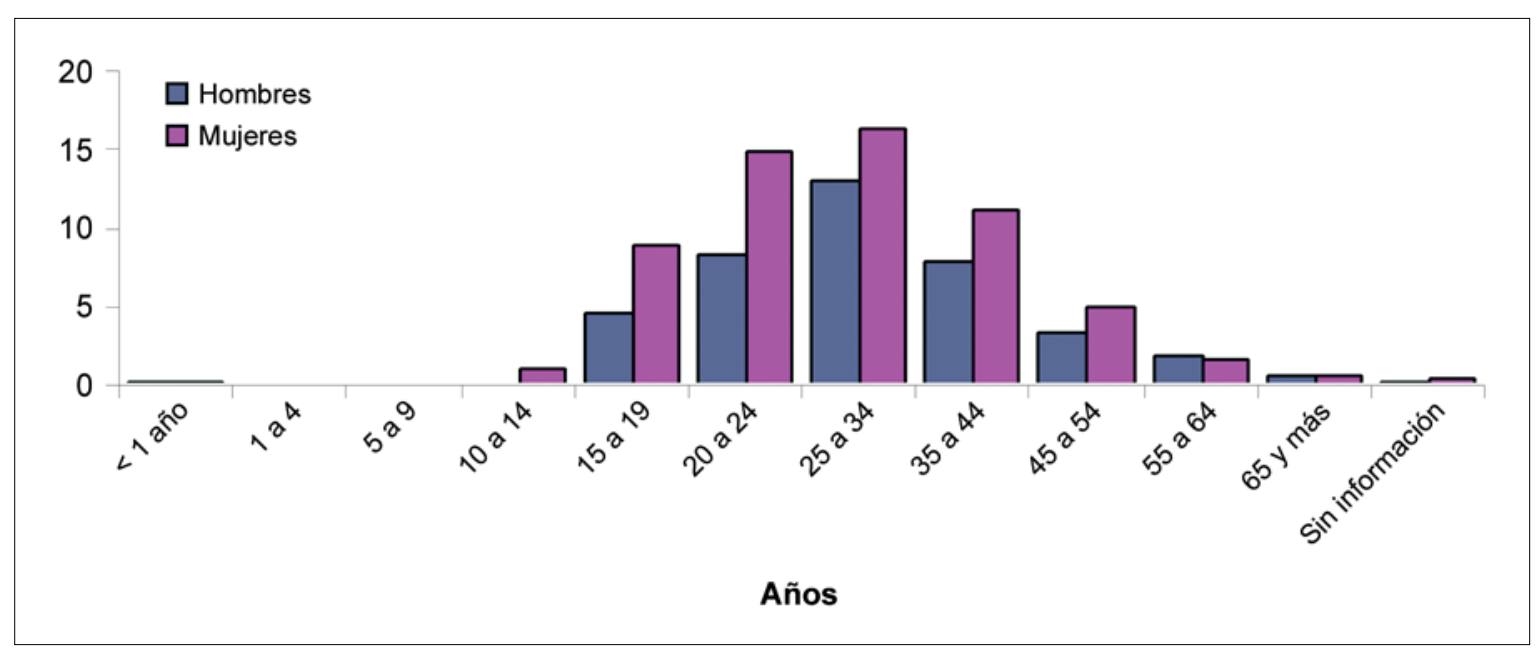

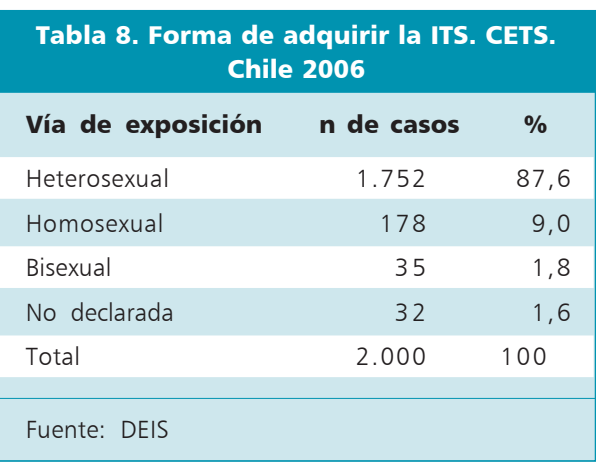

\begin{tabular}{|c|c|c|}
\hline$N^{\circ}$ de parejas & $\mathbf{n}$ & $\%$ \\
\hline Ninguna & 86 & 4,3 \\
\hline 1 & 1.043 & 52,2 \\
\hline 2 a 4 & 600 & 30 \\
\hline 5 a 9 & 115 & 5,8 \\
\hline Más de 10 & 126 & 6,3 \\
\hline Desconocido & 27 & 1,4 \\
\hline Total & 1.997 & 100 \\
\hline \multicolumn{3}{|l|}{ Fuente: DEIS } \\
\hline
\end{tabular}

\begin{tabular}{|lrc|}
\hline \multicolumn{3}{|c|}{$\begin{array}{c}\text { Tabla } \\
\text { con ITS. CETS. Chile } \mathbf{2 0 0 6}\end{array}$} \\
\hline Profesión u oficio & n & \% \\
\hline Dueña de casa & 502 & 25,1 \\
\hline Estudiante & 259 & 13,0 \\
\hline Comerciante & 154 & 7,7 \\
\hline Comercio sexual & 131 & 6,6 \\
\hline Obrero & 52 & 2,6 \\
\hline Chofer & 45 & 2,3 \\
\hline Asesora del hogar & 38 & 1,9 \\
\hline Secretaria & 24 & 1,2 \\
\hline Sin ocupación & 38 & 1,9 \\
\hline Otras & 754 & 38,0 \\
\hline Total & 1.997 & 100 \\
\hline
\end{tabular}

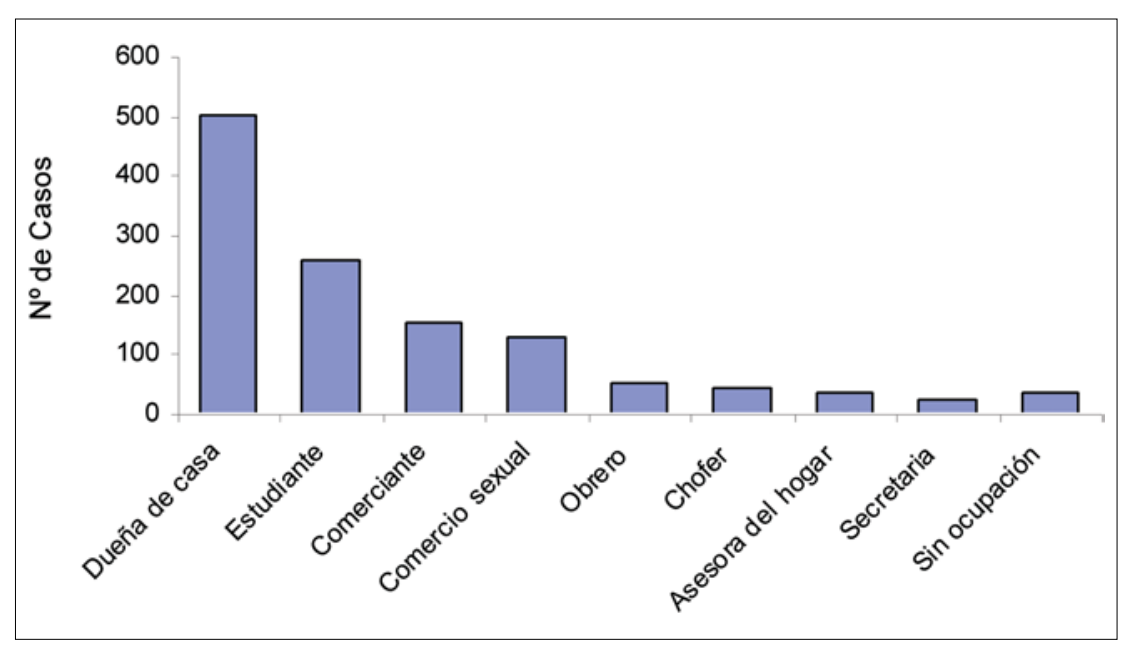

Figura 13. Casos notificados, según profesión u oficio declarado. CETS, Chile, 2006.
Actividades de la Unidad de Atención y Control en Salud Sexual (UNACESS)

En el entorno clínico:

- Consulta especializada de morbilidad en ITS.

- Control especializado de morbilidad en ITS.

- Consulta de salud sexual.

- Control de salud sexual.

- Atención a víctimas de violencia sexual.

En la atención complementaria:

- Educación personalizada.

- Consejería para la gestión de riesgo de ITS.

- Consejería pre y post prueba de ELISA para VIH.

- Manejo de la (s) pareja (s)/contacto (s) sexual (es). 


\section{Consulta especializada de morbilidad en ITS}

Definición: Es la atención especializada que se otorga en la UNACESS de un establecimiento de especialidades ambulatorias, a consultantes espontáneos y consultantes derivados de otras unidades o de Atención Primaria. Esta actividad es realizada por un(a) profesional médico Dermatólogo Venereólogo o por Gineco-Obstetra o Urólogo, ambos capacitados en ITS.

El desarrollo de la atención debe seguir la normativa estipulada en el manejo clínico de este documento.

\section{Actividades:}

- Diagnóstico y tratamiento según indicación de las presentes Normas.

- Notificación de casos (obligatoria y/o centinela) según corresponda, en formulario para ese efecto.

- Oferta y entrega de condones.

- Derivación a consejería con profesional o técnico capacitado.

\section{Control especializado de morbilidad en ITS}

Definición: Es la atención especializada que se otorga en la UNACESS de un establecimiento de especialidades ambulatorias, a consultantes que ya han tenido la primera consulta espontánea o son referidos desde otras unidades o centros de Atención Primaria. Esta actividad es realizada por un(a) profesional Médico Dermatólogo Venereólogo o por Gineco-Obstetra o Urólogo, ambos capacitados en ITS.

El desarrollo de la atención debe seguir la normativa estipulada en el manejo clínico de este documento.

\section{Actividades:}

- Control según indicación de las presentes normas.

- Oferta y entrega de condones.

- Derivación a consejería con profesional o técnico capacitado, en caso necesario.

\section{Consulta de salud sexual}

Definición: La consulta de salud sexual es una consulta voluntaria, espontánea o derivada, que tiene como objetivo principal apoyar la gestión de riesgo del/la consultante, solicitar, con consentimiento informado, exámenes si corresponde y promover la adherencia o cercanía a los servicios de salud disponibles, para disminuir el riesgo y facilitar el desarrollo y mantención de conductas preventivas.

Se ha definido como población objetivo de la consulta de salud sexual, las personas derivadas o en consulta espontánea que declaran:

- Ejercicio del comercio sexual

- Actividad sexual ligada al abuso del alcohol y drogas, sin uso o uso ocasional de preservativo.
- Actividad sexual con múltiples parejas (no comercio sexual) sin uso o uso ocasional de preservativo.

- El ejercicio del sexo anónimo, sexo grupal, cambio de parejas (swingers) sin uso o uso ocasional de preservativo.

Si durante la atención, el o la consultante declara ejercer el comercio sexual, se le ofrecerá la posibilidad de su adscripción voluntaria al control de salud sexual para las/los trabajadores sexuales disponible en la unidad, explicándole las características de éste.

Esta actividad clínica es realizada en la o las UNACESS por matrón (a), enfermero(a)-matrón(a), o por enfermero(a) capacitado(a).

\section{Actividades:}

- Orientación general respecto del control de salud sexual si corresponde.

- Anamnesis con énfasis en la identificación de factores de riesgo y derivación oportuna según corresponda.

- Examen clínico general (piel, mucosas).

- Examen clínico segmentario (boca y faringe, palpación en busca de adenopatías inguinales, ano, y genitales).

- Consejería y oferta de exámenes de acuerdo a necesidades o a exposición al riesgo:

- VDRL/RPR.

- Cultivo de flujo vaginal o uretral.

- Estudio de Chlamydophila sp y/o Mycoplasma sp.

- Estudio para N. gonorrhoeae (medio de ThayerMartin) cervical, anal y faríngeo.

- Prueba de ELISA para VIH.

- Antígeno de superficie de virus de hepatitis B.

- Oferta y entrega de condones.

- Derivación.

\section{Control de salud sexual}

Definición: Es el control de salud, bio-psico-social, periódico, que se ofrece a personas que ejercen el comercio sexual, dirigido hacia aspectos relacionados con la salud sexual y reproductiva y la mantención de condiciones saludables, con especial énfasis en la detección, tratamiento precoz de las ITS, así como en su prevención.

La asistencia a controles es voluntaria; sin embargo, la persona que se adscribe a este control debe aceptar las características de periodicidad de éstos.

La frecuencia recomendada es bimestral (cada dos meses).

En la Unidad o establecimiento donde se realiza el control de salud sexual se debe realizar cada seis meses un informe de la población bajo control, de acuer- 
do a las instrucciones del Gestor de Redes, quien a su vez deberá entregar los datos a la Autoridad Regional para la estadística sanitaria (Código Sanitario, Párrafo II: De las enfermedades venéreas $)^{9}$.

La actividad clínica y el informe estadístico es realizada por matrón (a) enfermero(a)-matrón(a) o por enfermero(a) capacitado(a)

\section{Actividades}

Control de salud en trabajadoras sexuales mujeres:

- Orientación general respecto del control de salud sexual.

- Anamnesis con énfasis en la identificación de factores de riesgo y derivación oportuna según corresponda.

- Examen clínico general (piel, mucosas).

- Examen clínico segmentario (cavidad oral y faringe, mamas, palpación en busca de adenopatías inguinales, ano, vulva y vagina).

- Especuloscopia y tacto vaginal.

- Oferta de exámenes y consejería de acuerdo a la clínica o a exposición al riesgo ${ }^{10}$.

- VDRL/RPR.

- Cultivo cervical y vaginal.

- Estudio de Clamydophila sp y/o Mycoplasma sp.

- Estudio para N. gonorrhoeae (medio de ThayerMartin) cervical, anal y faríngeo.

- Antígeno de superficie de virus de hepatitis B.

- Prueba de ELISA para VIH.

$\begin{array}{ll}\text { Frecuencia mínima de exámenes } \\ \text { Examen } & \text { Frecuencia } \\ \text { VDRL/RPR } & 6 \text { meses } \\ \text { HBsAg } & 12 \text { meses } \\ \text { Gram directo } & 4 \text { meses } \\ \text { Cultivo en Thayer Martin } & 6 \text { meses } \\ \text { Papanicolau } & 12 \text { meses } \\ \text { Prueba de ELISA para VIH } & \begin{array}{l}\text { Según exposición al } \\ \text { riesgo. }\end{array}\end{array}$

Se recomienda repetir exámenes según evaluación clínica:

- Derivación a consulta de morbilidad.

- Derivación a consejería en gestión de riesgo ITS.

- Orientación para la vida sexual en pareja (no cliente).

- Educación personalizada.

- Entrega de condones.
- Consejería en salud sexual y reproductiva.

- Prescripción, control y seguimiento de métodos de regulación de la fertilidad, si corresponde.

- Establecer referencia y contra-referencia con los establecimientos de la red.

- Registro en documentos vigentes: ficha clínica, informe diario de actividades, estadística mensual.

- Realizar censo cada seis meses de la población bajo control.

Control de salud en trabajadores sexuales hombres:

- Orientación general respecto del control de salud sexual.

- Anamnesis con énfasis en la identificación de factores de riesgo.

- Examen clínico general.

- Examen clínico segmentario (cavidad oral y faringe, palpación en busca de adenopatías inguinales, ano, pene y testículos).

- Oferta de exámenes y consejería de acuerdo a la clínica o a exposición al riesgo ${ }^{11}$ :

- VDRL/RPR.

- Estudio de flujo uretral y anal si corresponde.

- Estudio de Chamydophila sp y/o Mycoplasma sp.

- Estudio para N. gonorrheae (medio de Thayer Martín) anal y faríngeo.

- Prueba de ELISA para VIH.

- Derivación a consulta de morbilidad si corresponde.

Frecuencia mínima de exámenes

$\begin{array}{ll}\text { Examen } & \text { Frecuencia } \\ \text { VDRL/RPR } & 6 \text { meses } \\ \text { HBsAg } & 12 \text { meses } \\ \text { Gram directo uretral } & 4 \text { meses } \\ \text { Cultivo en Thayer Martin } & 6 \text { meses } \\ \text { Prueba de ELISA para VIH } & \begin{array}{l}\text { Según exposición al } \\ \text { riesgo. }\end{array}\end{array}$

- Derivación a consejería en gestión de riesgo en ITS.

- Orientación para la vida sexual en pareja (no cliente).

- Educación personalizada.

- Entrega de condones ${ }^{12}$.

- Referencia y contra-referencia con los establecimientos de la red.

- Registro en documentos vigentes: ficha clínica, informe diario de actividades, estadística mensual.

- Realizar censo de población bajo control cada seis meses.

9 Art. 41: "Para las personas que se dedican al comercio sexual, se llevará una estadística sanitaria".

${ }^{10}$ Los exámenes deben ser tomados con el consentimiento de la persona, lo cual debe quedar consignado en la ficha clínica. En el caso de la prueba de ELISA para VIH, el consentimiento informado debe ser guardado en la unidad, sea éste de aceptación o rechazo.

${ }^{11}$ Los exámenes deben ser tomados con el consentimiento de la persona, lo cual debe quedar consignado en la ficha clínica. En el caso de la prueba de ELISA para VIH, el consentimiento informado debe ser guardado en la unidad, sea éste de aceptación o rechazo.

${ }^{12}$ De preferencia extra-resistentes y con lubricante adicional. 
Observación: La consulta y el control de salud sexual de personas transexuales y travestis debe adecuarse a las indicaciones entregadas de acuerdo al sexo del consultante, e incluir tanto su condición de transgeneras (o) como su orientación sexual como parte del proceso de consejería.

\section{Atención a víctimas de violencia sexual}

Las Normas y Guía Clínica para la atención en servicios de urgencia de personas víctimas de violencia sexual $^{13}$ establecen que las personas atendidas por esta causa deben ser evaluadas en estos establecimientos, donde se indicará de acuerdo a cada caso, el tratamiento profiláctico para evitar las ITS. En ese documento se recomienda, además, derivar a los centros de ETS, (ahora UNACESS), para ser atendidas por profesionales capacitados que puedan realizar el seguimiento adecuado.

Por lo anterior, la atención otorgada en la UNACESS a personas que han sido víctimas de violencia sexual debe apoyar la primera atención recibida en los centros de urgencia.

La atención de víctimas de violencia sin atención de urgencia previa se orienta a:

- La profilaxis, diagnóstico, tratamiento, y seguimiento clínico de las ITS cuando corresponda.

- Derivación a salud mental para atención especializada y a otras especialidades médicas si procede.

El examen médico debe ajustarse en forma rigurosa a los signos clínicos observados y a los hallazgos objetivos. Deberá dejar constancia de la conclusión clínica, sin afirmar o calificar el delito, por si los antecedentes son requeridos como parte del peritaje.

La infección por N. gonorrhoeae, Chlamydophila sp, Trichomonas sp, T. pallidum y la vaginosis bacteriana pueden ser prevenidas con la administración de una asociación de antimicrobianos.

Los criterios para decidir tipo de antimicrobiano y dosis son: la edad del consultante, posibilidad de un embarazo en la víctima, y posibles alergias (Figura 14).

\section{Atención complementaria}

Educación personalizada

La educación personalizada es la actividad realizada por médico, matrón (a) enfermero(a)-matrón(a) o por enfermero(a) capacitado(a), que se desempeña en la UNACESS. Esta actividad se define en términos de la aplicación del modelo educativo en la prevención de las ITS. Se puede realizar simultáneamente con la atención clínica.

\section{Modelo educativo en la prevención de las ITS}

Los objetivos principales de la educación del consultante sobre ITS son los siguientes:

- Informar acerca de la infección que presenta el o la consultante que acude a la UNACESS.

- Prevenir la re-infección y la adquisición de otras ITS.

- Cortar la cadena de transmisión.

- Evitar las complicaciones de las ITS.

Para cumplir con estos objetivos las UNACESS deben instalar un modelo educativo que produzca una sinergia entre el tratamiento y la prevención.

El tratamiento farmacológico tiene más efectividad cuando se combina con la educación de el/la consultante. La entrega de información esencial motiva a éste a seguir las recomendaciones terapéuticas y facilita la toma de decisiones sobre su salud.

La educación del consultante sobre ITS contempla la prevención de la re-infección de la enfermedad actual y la prevención de infecciones futuras, para lo cual promueve prácticas sexuales más seguras, de tal manera de que éste pueda acceder a un cambio de comportamiento orientado a las prácticas sexuales de bajo riesgo.

El dominio de conocimientos no garantiza la prevención de las ITS. Es necesario contextualizar la información y considerar el entorno bio-psico-social que constituye el mundo de vida del consultante. En consecuencia, los y las profesionales que se desempeñan en las UNACESS, deben desarrollar habilidades que les permitan orientar a sus consultantes, respetando sus estilos de vida.

Uno de los aspectos importantes en la educación del consultante es la entrega de material gráfico que complemente el contenido verbal de la información entregada, y tenga un efecto didáctico y multiplicador (folletería).

Finalmente, es necesario compartir con el/la consultante las técnicas adecuadas para el uso correcto del condón, visualizando las posibles dificultades en la negociación del uso con la pareja.

La aplicación del modelo educativo contempla las siguientes acciones:

\footnotetext{
${ }^{13}$ En el punto 3.2 de las Normas y Guía Clínica para la atención en servicios de urgencia de personas víctimas de violencia sexual "Las medidas efectivas para prevenir una infección como consecuencia de la posible exposición durante la agresión sexual, tanto en hombres como mujeres, pueden ser diferida - evitando así la sobrecarga de indicaciones a la víctima en un primer momento - sólo si se tiene la seguridad de que la persona podrá acudir dentro de los dos días siguientes a la atención de urgencia, a un Centro de Enfermedades de Transmisión Sexual (CETS). En general, se recomienda indicar el tratamiento y de todas maneras derivar a la persona al CETS del Servicio de Salud correspondiente que cuente con profesionales capacitados, métodos de apoyo diagnóstico y oferta de consejería y control de seguimiento.
} 


\section{Momentos}

Momento 1:

Recepción y acogida de el/la consultante

Momento 2: Indagación y registro de datos

\section{Objetivo}

- Establecer contacto con el o

la consultante

\section{Actividades}

- Saludo y presentación

- Preguntar el motivo de consulta

- Explicar el sentido de la consejería y las condiciones bajo las cuales se realiza

- Preguntar asertivamente los aspectos relacionados con comportamiento sexual y riesgo:

- No parejas sexuales

- Uso de condón

- Consumo y/o abuso de drogas y alcohol

- Concepto personal de riesgo

- Situación de violencia sexual

- Consignar en documento vigente la información relevante

Momento 3:

Entrega de información pertinente
- Informar acerca de las ITS en relación a la gestión de riesgo
- Entregar información acerca de la infección que origina la consulta, si corresponde

- Compartir información general sobre las ITS, sus formas de transmisión, prevención y tratamiento, con énfasis en las situaciones de riesgos expresadas por el/la consultante

- Reforzar conocimientos previos y modificar conocimientos errados

- Evaluar en conjunto con el/la consultante su historia y su proyecto de vida, en relación a la percepción de riesgo

- Explicar la importancia de cumplir el tratamiento, evitando la automedicación

- Enfatizar la relación entre ITS y VIH/SIDA

- Realizar consejería pre examen, si se oferta prueba de ELISA para VIH

- Informar sobre medidas de prevención y entregar material gráfico pertinente

- Explicar los beneficios del uso correcto del condón

- Facilitar el reconocimiento de las responsabilidades individuales en el autocuidado y las posibilidades de superar los problemas

- Revisar con el/la consultante, si corresponde, el efecto del alcohol y las drogas en alteraciones para la percepción de riesgo y la capacidad de autocuidado

- Evaluar y recomendar otras prácticas de sexo más seguro

- Estimular la autoestima y la confianza de el/la consultante

- Destacar la importancia de romper la cadena de transmisión con su(s) pareja(s) para lo cual se recomienda la asistencia de ésta a control.

- Reforzar ideas fuerza en torno a la prevención, Síntesis tratamiento y control

- Incentivar la realización de preguntas

- Clarificar conceptos confusos y aclaración de dudas

- Acuerdos tomados en conjunto

- Señalar los mecanismos administrativos que se deben seguir para facilitar la asistencia a control

- Dar citación para el próximo control si las condiciones lo permiten

- Realizar derivación a otras unidades si fuere necesario

- Registro de las labores realizadas

\section{Observaciones}

Poner énfasis en:

- Si es primera consulta enfatizar el sentido de la consejería y en la confidencialidad

- Si ha recibido consejería previa enfatizar el sentido de la nueva consulta.

- Formular preguntas que abran la conversación, permitiendo recabar información y clarificar lo que la persona dice

- Enfatizar en lo relacionado con la infección que origina la consulta, si ésta se deriva de la consulta de morbilidad, u orientarla hacia la percepción de riesgo si ésta responde a la necesidad surgida desde la consulta o el control de salud sexual

- Hablar en términos claros y precisos, cuidando de evaluar la comprensión por parte de el/la consultante, respetando su cultura, valores y creencias

- Si la consejería da origen a la toma de la prueba de ELISA para VIH, enfatizar que la certeza del resultado depende de la fecha de exposición al riesgo
- Enfatizar acerca de la confidencialidad de la consejería recién realizada y de las posteriores, si procede 
La atención a la pareja debe considerar el principio de confidencialidad y el carácter voluntario, es decir, no debe ser obligatoria.

Nunca se forzará la divulgación de la información sobre sus contactos sexuales, y los datos sobre su identidad serán del conocimiento exclusivo del equipo que lo atiende.

Esta situación está estipulada en el Reglamento sobre Infecciones de Transmisión Sexual ${ }^{14}$ y en las normas de la Ley $\mathrm{N}^{\circ} 19.628$, sobre protección de la vida privada en lo concerniente a datos de carácter personal, y con el debido resguardo por parte de los funcionarios que tengan acceso a ellos del secreto profesional y del secreto estadístico establecido en la Ley $\mathrm{N}^{\circ}$ 17.374, obligación que no cesa por haber terminado sus actividades en ese campo.

Para intervenir en la cadena de transmisión de las ITS, la atención de el/la consultante debe considerar:

- Tratamiento a todas las parejas sexuales de el/la consultante.

- Tratamiento de las mismas ITS que presenta el o la consultante, aún cuando el/la pareja no tenga signos de ellas.

\section{Metodologías para facilitar la comunicación a la pareja y la derivación para la atención Referencia por el/la consultante}

El/la consultante asume la responsabilidad de ponerse en contacto con sus parejas sexuales y pedirles que soliciten atención.

Existen innumerables razones por las que no quieren o no pueden hablar de las ITS con su pareja/ contacto. En estos casos, el profesional de la salud tiene la responsabilidad de facilitar la búsqueda y decisión de la forma de abordar este tema.

- Una posibilidad es que el/la consultante explique a su o sus contactos sexuales, en forma directa, la ITS diagnosticada y la necesidad de tratamiento para la misma.

- Otra alternativa es que el/la consultante invite a su pareja al lugar donde se está atendiendo. En caso de que el/la consultante desee que su/sus pareja(s) asista(n) sola(s), se le puede entregar una citación de referencia a la unidad. En ambos casos la explicación del diagnóstico y tratamiento será entregada por el equipo tratante.

\section{Referencia profesional}

$\mathrm{El} /$ la consultante $\mathrm{NO}$ asume la responsabilidad de ponerse en contacto con sus parejas/contactos sexuales y pedirles que soliciten atención, sino que deja esta responsabilidad en el equipo que lo atiende.

El personal de salud que realizará la citación de personas dadas como contacto debe estar capacitado para contactar a la/las pareja(s) sexual(es) de los/las consultantes.

Esta decisión debe tener un consentimiento informado por el/la consultante (caso índice) en la ficha de manera que se puedan llevar a cabo los siguientes procedimientos:

- Uno de los miembros del equipo se pone en contacto con las parejas referidas por el/la consultante de ITS. Puede ser el mismo profesional que atendió y trató al paciente originalmente, $\mathrm{u}$ otra persona que desempeña una función especial en relación con la búsqueda y atención de los contactos sexuales. El profesional de la salud es quien pide a la(s) pareja(s) que vaya(n) al establecimiento en busca de tratamiento.

- El contacto puede ser vía telefónica o mediante citación al establecimiento en carta certificada.

Dado que la referencia profesional tiene un costo demasiado alto, y porque se puede entender como un atentado a la confidencialidad de la atención, la opción más práctica es la referencia por el paciente. Este es el método que recomienda la OMS.

En algunos casos puede ser necesario compartir la información con otras unidades. Por ejemplo, si se diagnostica una ITS a una consultante en una unidad de atención prenatal, su pareja probablemente se atienda en un lugar diferente. Sería importante, por lo tanto, que el personal de salud esté coordinado en estos aspectos y que exista un flujograma claro de la atención.

\footnotetext{
${ }^{14}$ Artículo $\mathrm{N}^{\mathrm{o}}$ 6: Todos los antecedentes y documentos relacionados con la notificación e investigación epidemiológica de las infecciones de transmisión sexual, serán estrictamente confidenciales, de conformidad con las normas de la Ley $\mathrm{N}^{\circ} 19.628$ sobre protección de la vida privada en lo concerniente a datos de carácter personal, y con el debido resguardo por parte de los funcionarios que tengan acceso a ellos del secreto profesional y del secreto estadístico establecido en la ley $\mathrm{N}^{\circ} 17.374$, obligación que no cesa por haber terminado sus actividades en ese campo. Dichos antecedentes sólo serán entregados a requerimiento del interesado o de la autoridad judicial.
} 